\title{
A rare case of early onset severe preeclampsia with PRES
}

\author{
Sanjay Singh ${ }^{1 *}$, Debkalyan Maji², Shakti Vardhan ${ }^{1}$
}

\begin{abstract}
${ }^{1}$ Department of Obstetrics and Gynecology, Armed Forces Medical College, Pune, Maharashtra, India
${ }^{2}$ Department of Obstetrics and Gynecology, 166 Military Hospital, Jammu, India
\end{abstract}

Received: 24 December 2017

Accepted: 24 January 2018

\section{*Correspondence:}

Dr. Sanjay Singh,

E-mail: drsanjaysingh@gmail.com

Copyright: ( $)$ the author(s), publisher and licensee Medip Academy. This is an open-access article distributed under the terms of the Creative Commons Attribution Non-Commercial License, which permits unrestricted non-commercial use, distribution, and reproduction in any medium, provided the original work is properly cited.

\begin{abstract}
Posterior reversible encephalopathy syndrome (PRES) is a cliniconeuroradiological syndrome. Patients usually present with seizures, visual disturbances, headache, and altered mental state. Most accepted pathophysiology is vasogenic edema. Imaging predominantly shows parieto-occipital white matter changes. We report a 22-year-old G2P1L1 lady who presented at 23 weeks 2 days period of gestation (POG) with high blood pressure $(160 / 104 \mathrm{~mm}$ of $\mathrm{Hg}$ ) and headache and later on developed diminished vision too. There was no sensory motor deficit. After evaluation a plan of termination of pregnancy was made, in consultation with the patient and her husband. She was put on prophylactic dose of Inj. $\mathrm{MgSO}_{4}$ and anti-hypertensives and termination of pregnancy was done with intracervical application of PGE2 gel followed by vaginal PGE1 tablet (Misoprost) application. Her vision and headache however, didn't improve even though she was put on $\mathrm{Inj} \mathrm{MgSO}_{4}$ and $\mathrm{BP}$ was controlled with antihypertensive. She delivered within 10 hours. In view of persistence of her symptoms, a MRI brain was done in consultation with a neurophysician, two hours after the delivery that suggested edema in occipital and temporal lobe suggestive of posterior reversible encephalopathy syndrome. Approximately 6-8 hours after delivery, gradual clinical improvement in visual acuity and headache was noted. Her vision completely recovered in 6 days. This case highlights the importance of keeping this entity in mind for the prompt diagnosis and early management, thus preventing short and long-term neurological deficits in this reversible condition popularly known as PRES.
\end{abstract}

Keywords: Eclampsia, Leukoencephalopathy syndrome, Preeclampsia, Pregnancy, Posterior reversible encephalopathy syndrome (PRES), Reversible posterior

\section{INTRODUCTION}

Posterior reversible encephalopathy syndrome (PRES) is a cliniconeuroradiological syndrome. It was first identified by Hinchey et al in $1996 .{ }^{1}$ Common clinical conditions associated with this syndrome include chronic hypertension, chronic kidney disease, certain autoimmune diseases, exposure to certain immunosuppressive drugs and chemotherpy especially in context to organ transplantation. ${ }^{2}$
Patients usually present with seizures, visual disturbances, headache, and altered mental state. Most accepted pathophysiology is vasogenic edema. Imaging predominantly shows parieto-occipital white matter changes. $^{3}$

Awareness about this entity and high level of suspicion is required to recognise it. The timely diagnosis helps preventing the long-term sequelae of this reversible condition popularly known as PRES. Here we present a case of early onset severe preeclampsia complicated with PRES. 


\section{CASE REPORT}

A 22 years G2P1L1 lady at 23 weeks 2-day POG with Rh negative non alloimmunized pregnancy presented with history of headache and pain right hypochondrium. She was a booked case with unremarkable earlier antenatal visits. She was normotensive in all her previous checkups. On arrival her blood pressure (BP) was recorded as $160 / 104 \mathrm{~mm}$ of $\mathrm{Hg}$. She was afebrile, and the pulse rate and respiratory rate were normal. There was no pedal edema. The cardiovascular and respiratory system was essentially normal. On central nervous system examination there was no sensory motor deficit. Per abdominally liver and spleen were not palpable, and the Murphy's sign was negative. The fundal height was clinically corresponding to 22 weeks period of gestation. The laboratory tests done after admission suggested: $\mathrm{Hb} \%$ - $11.3 \mathrm{gm} \%$, TLC - $11500 / \mathrm{mm}^{3}$, platelet count 2.6 lakh $/ \mathrm{mm}^{3}$, serum creatinine - $0.7 \mathrm{mg} / \mathrm{dl}$, urea - 19 $\mathrm{mg} / \mathrm{dl}$, uric acid - $4.9 \mathrm{mg} / \mathrm{dl}$, bilirubin - 0.2mg/dl, SGOT 33 IU/L, SGPT - 30 IU/L, LDH - 295 IU/L and urine dipstick test for protein-trace. 24 hours urinary protein was $300 \mathrm{mg}$. Peripheral blood smear (PBS) didn't show any feature of hemolysis. Sonography suggested normal liver and gallbladder. Fundoscopy examination was normal. She was initially put on $\alpha$-methyl DOPA $500 \mathrm{mg}$ three times a day to control blood pressure with a target range of systolic BP of $140-150 \mathrm{~mm}$ of $\mathrm{Hg}$ and diastolic BP of 90-100 $\mathrm{mm}$ of $\mathrm{Hg}$. Though the patient became asymptomatic after 24 hours, but the BP kept on rising, requiring further increase in the dose of $\alpha$-methyl DOPA and subsequent addition of tab labetalol 100mg three times a day.

On $3^{\text {rd }}$ admission day she developed blurring of vision with recurrence of headache. Blood pressure of the patient rose to $166 / 106 \mathrm{~mm}$ of $\mathrm{Hg}$, in spite of taking antihypertensives as mentioned above. On examination of the central nervous system there was no focal neurological deficit. Ophthalmological examination revealed restricted vision in both eyes limited to finger counting at $1 \mathrm{ft}$ distance. However, fundoscopy examination was normal. Lab investigations suggested: $\mathrm{Hb} \%$-12.3 gm\%, TLC - $12100 / \mathrm{mm}^{3}$, Platelet count $2.81 \mathrm{lakh} / \mathrm{mm}^{3}$, random blood sugar - $102 \mathrm{mg} \%$, blood creatinine - $1 \mathrm{mg} / \mathrm{dl}$, urea - $23 \mathrm{mg} / \mathrm{dl}$, uric acid - 5.9 $\mathrm{mg} / \mathrm{dl}$, bilirubin-0.4mg/dl, SGOT - 28 IU/L, SGPT - 22 IU/L, LDH - 762 IU/L and urine dipstick test for protein $3+$. PBS again ruled out hemolysis. Ultrasonography suggested a single live fetus with mean gestational age of 22 wks 6 days with effective fetal weight of $523 \pm 78$ gms. Bilateral uterine artery showed high resistance flow with persistent diastolic notch and absent diastolic flow in the umbilical artery (Figure 1). Diagnosed as a case of imminent eclampsia a decision of termination of pregnancy (with intracervical $\mathrm{PGE}_{2}$ gel, followed by tablet misoprostol) was taken, after due counselling and consent of the patient and her husband. They didn't give consent for cesarean section to salvage the fetus. She was put on Inj. $\mathrm{MgSO}_{4}$ to prevent seizure as per Zuspan regime and Inj. Labetalol to control the BP. However, in spite of Inj. $\mathrm{MgSO}_{4}$ infusion and control of BP with Inj. Labetatol her visual acuity and intensity of headache didn't improve. 10 hours after $\mathrm{PGE}_{2}$ gel application she delivered a $498 \mathrm{gm}$ of a fresh still born female fetus with no detectable external morphological abnormality. Placenta was $220 \mathrm{gm}$ with triple vessels in umbilical cord. In view of no improvement in her vision and headache, in spite of use of Inj. $\mathrm{MgSO}_{4}$ and control of BP with antihypertensive, MRI brain was done 2 hours after the delivery, in consultation with neurophysician that showed edema in left occipital and temporal lobe suggestive of PRES (Figure 2).

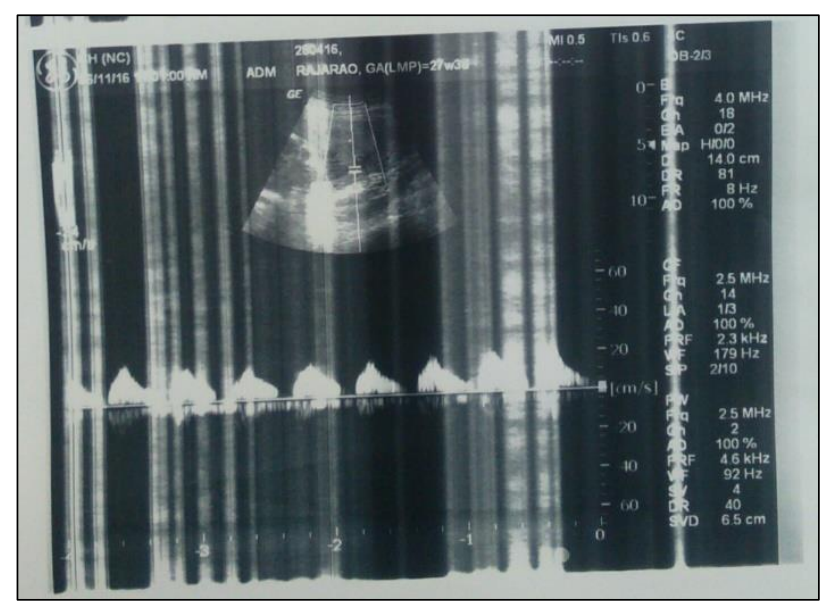

Figure 1: Colour Doppler of umbilical artery with absent diastolic flow.

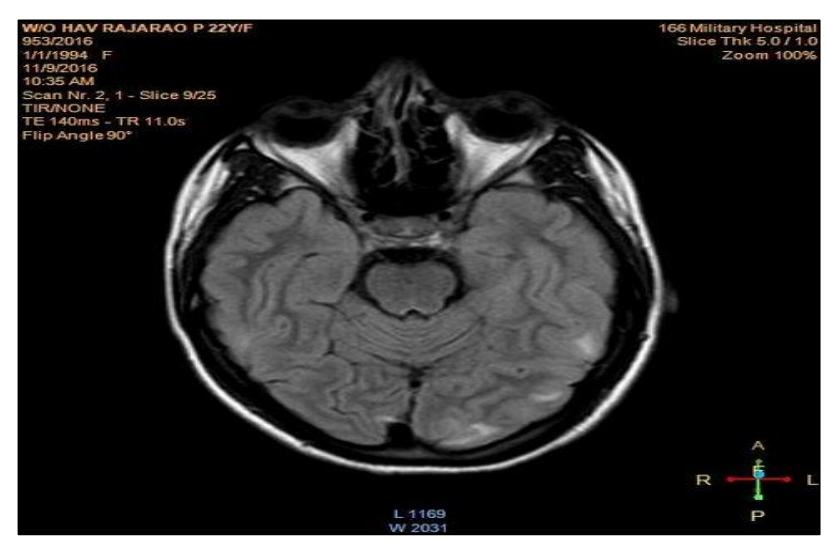

Figure 2: MRI brain shows patchy focal

hyperintensity in the left temporo-occipital region suggestive of edema.

Post-delivery, approximately after 6-8 hours, there was gradual improvement in her vision and severity of headache. She was continued on Inj. $\mathrm{MgSO}_{4}$ infusion till 24 hrs post-delivery and was switched over from Inj. Labetalol to tablet Amlodipine $5 \mathrm{mg}$ once a day for control of BP. Her vision completely recovered in 6 days. She was discharged from the hospital on $9^{\text {th }}$ post-partum day. Since she had completely recovered, the MRI was not repeated. The patient is under follow up for more than 
one year now and is normotensive without any medication and is asymptomatic.

\section{DISCUSSION}

PRES is a clinical and radiological syndrome. Several other terminologies have also been used in literature to address this entity namely, posterior reversible leukoencephalopathy syndrome, hypertensive encephalopathy, hyperperfusion encephalopathy, brain capillary leak syndrome and reversible posterior cerebral edema syndrome. ${ }^{4}$ It was identified and reported by Hinchey et al in $1996 .^{1}$

Though PRES is an increasingly recognized disorder, it's true incidence is still not clearly known. PRES may be considered a misnomer as the image changes and clinical features are not always limited to the posterior cerebral hemispheres. ${ }^{5}$ In the present case it was there in left sided temporo-occipital region of the brain. Moreover, clinical and radiological findings are not always reversible as it may get complicated by ischemic or haemorrhagic stroke leading to chronic seizure disorder or death of the individual. $^{6}$

Several well-known co-morbidities or medical conditions that trigger PRES are: chronic hypertension (>50\%), chronic kidney disease $(38 \%)$, autoimmune diseases: including thrombotic thrombocytopenic purpura and systemic lupus erythematosus (45\%) and exposure to immunosuppressive drugs such as cyclosporine, tacrolimus or chemotherapy especially in context to organ transplantation. ${ }^{2}$ Acute hypertension is the commonest trigger as could be seen in our case and in PRES the common causes of acute hypertension is acute kidney injury, preeclampsia and eclampsia, cases of autonomic disturbance, e.g. Guillain-Barré syndrome and after illicit drug use..$^{2,7}$

PRES generally evolves over very short span of time (within hours) and the patient presents with rapid onset of symptoms including seizures, visual disturbances, headache, and altered mental state., ${ }^{2,7}$ Diminished vision and headache was the presenting complaint of our patient. As mentioned above it is often associated with acute hypertension but $10 \%-30 \%$ of patients have normal or only mildly elevated blood pressure..$^{2,7,8}$ It is important to note that the severity of clinical symptoms may vary, for example the visual disturbance may be in the form of blurred vision, homonymous hemianopsia, or even cortical blindness ${ }^{8}$. Nausea, vomiting, and brainstem deficits are the less commonly seen symptoms. ${ }^{8}$ Neurologically, patients may be mildly confused or agitated, but can become comatose also. ${ }^{8}$ Though seizures and status epilepticus are common, nonconvulsive status epilepticus may be more frequent than generalized status epilepticus. ${ }^{9}$ Probably because of timely initiation of Inj $\mathrm{MgSO}_{4}$ infusion, our patient didn't throw fits.
Even though, almost two decades have elapsed since PRES was described, the cause of it remains unclear and controversial. The most popular theory is that the severe hypertension causes interruption to brain autoregulation leading to hyperperfusion and cerebral vessel damage, resulting in interstitial extravasation of proteins and fluids, causing vasogenic edema. ${ }^{8,10}$ However, the autoregulation theory does not explain why PRES may occur even in a normotensive patient or in a case with mildly elevated BP too and why the extent of the edema is not directly related to the severity of the BP. ${ }^{2,7,8}$ The alternative theory is that of a systemic inflammatory state causing endothelial dysfunction causing hypoxia and subsequent vasogenic edema. ${ }^{10}$ This postulate is based on an observation that PRES is usually associated with a systemic inflammatory process like sepsis, eclampsia, transplantation, and autoimmune disease. ${ }^{10}$ However, this theory fails to explain why some cases of PRES seem to occur in the absence of any inflammatory state. Though association between pregnancy associated hypertension and PRES is well known, the cause and effect relationship is still debatable.

The important differential diagnosis of PRES is varied and is required to be excluded carefully because the management may differ. These are: venous sinus thrombosis or subdural, intracerebral, or subarachnoid hemorrhage, infective encephalitis or meningitis, posterior circulation stroke, (may require urgent thrombolysis), basilar artery thrombosis, central nervous system vasculitis, autoimmune encephalitis and metabolic encephalopathies such as deranged serum glucose, sodium, uremia, or drug toxicity (e.g. cyclosporine). ${ }^{11}$

Though computed tomography (CT) imaging allows for rapid assessment in acute cases and also helps in exclusion of major cerebral hemorrhage, space-occupying lesions, venous sinus thrombosis or arterial ischemia or thrombosis, its sensitivity is not very high to detect cases of PRES. Thus, MRI is recommended modality. Typical MRI findings in PRES are: bilateral white-matter abnormalities in the posterior regions of both cerebral hemispheres, affecting mainly the occipital and parietal lobes. ${ }^{2,7,10}$ In the present case there was left sided temporo-occipital edema of the brain. The possible common atypical features are: hemorrhage, asymmetrical changes, isolated involvement of the frontal lobes, and cortical lesions. ${ }^{2,7,10}$ Magnetic resonance venography has the advantage of not requiring nephrotoxic contrast. However, it may not be available in all centers. Angiography can identify vessel thrombosis, dissection, or vasculitis. There has been no randomized control trial to suggest the management of PRES. However, timely and rapid withdrawal of the trigger appears to be the key thing in its management. It hastens recovery and avoids complications.

This includes aggressive blood pressure management, withdrawal of the causative drug, or prompt delivery in severe preeclampsia or eclampsia. ${ }^{8}$ Antiepileptic drugs 
are required to be used to treat seizures. The timely termination of pregnancy, control of BP and use of prophylactic MgSO4 to prevent eclampsia, in our case lead to rapid and complete clinical recovery of our patient. Patients with status epilepticus may require general anaesthesias and ventilator support. Corticosteroids though used by many, have not been proven to be effective in reduction of cerebral edema. ${ }^{8}$ Prompt recognition and early treatment are very important to avoid the permanent damage leading to sequelae and even mortality, as can be seen in the present case.

If promptly recognized and treated, the clinical syndrome usually resolves within a week and the changes seen in magnetic resonance imaging (MRI) resolve over days to weeks. ${ }^{8,12,2}$ Radiologic resolution can take weeks despite the more rapid clinical recovery. ${ }^{2,8}$ Persistent neurologic deficits have been reported, but are rare. ${ }^{8}$ Our patient showed features of improvement in her visual acuity and headache approximately 6-8 hours after delivery and her vision completely recovered in 6 days. Since there was very rapid clinical recovery of our case after delivery, follow up neuroimaging was not done.

\section{CONCLUSION}

Present case had presented with signs and symptoms of early onset severe preeclampsia and thus was managed accordingly. In view of no improvement of the headache and the visual acuity of the patient, in spite of the use of Inj $\mathrm{MgSO}_{4}$ and control of BP with antihypertensive, the MRI was done, that helped us to diagnose PRES. Since there was very rapid clinical recovery after delivery, follow up neuroimaging was not done. The complete clinical recovery of our patient emphasises the need for early diagnosis and treatment of PRES so that the shortand long-term neurological sequelae may be prevented. Though association between pregnancy associated hypertension and PRES is well known, the cause and effect relationship is still debatable.

\section{Funding: No funding sources}

Conflict of interest: None declared

Ethical approval: Not required

\section{REFERENCES}

1. Hinchey J, Chaves C, Appignani B, Breen J, Pao L, Wang A, et al. A reversible posterior leuko- encephalopathy syndrome. Engl J Med. 1996;334:494-500.

2. Fugate JE, Claassen DO, Cloft HJ, Kallmes DF, Kozak OS, Rabinstein AA. Posterior reversible encephalopathy syndrome: associated clinical and radiologic findings. Mayo Clin Proc. 2010;85:42732.

3. Bartynski WS, Boardman JF. Distinct imaging patterns and lesion distribution in posterior reversible encephalopathy syndrome. AJNR Am J Neuroradiol. 2007;28:1320-7.

4. Calabrese LH, Dodick DW, Schwedt TJ, Singhal AB. Narrative review: reversible cerebral vasoconstriction syndromes. Ann Internal Med. 2007;146(1):34-44,

5. Stott VL, Hurrell MA, Anderson TJ. Reversible posterior leukoencephalopathy syndrome: a misnomer reviewed. Internal Med J. 2005;35(2):8390.

6. Pratap JN, Down JF. Posterior reversible encephalopathy syndrome: a report of a case with atypical features. Anaesthesia. 2008;63(11):1245-8.

7. McKinney AM, Short J, Truwit CL, McKinney ZJ, Kozak OS, SantaCruz KS, et al. Posterior reversible encephalopathy syndrome: incidence of atypical regions of involvement and imaging findings. AJR Am J Roentgenol. 2007;189:904-12.

8. Roth C, Ferbert A. The posterior reversible encephalopathy syndrome: what's certain, what's new? Pract Neurol. 2011;11:136-44.

9. Kozak OS, Wijdicks EF, Manno EM, Miley JT, Rabinstein AA. Status epilepticus as initial manifestation of posterior reversible encephalopathy syndrome. Neurol. 2007;69:894-7.

10. Bartynski W. Posterior reversible encephalopathy syndrome, part 1: fundamental imaging and clinical features. AJNR Am J Neuroradiol. 2008;29:1036-42.

11. Esther V, Hobson, Craven I, Blank SC. Posterior reversible encephalopathy syndrome: a truly treatable neurologic illness. Perit Dial Int. 2012;32(6):590-4.

12. Hinchey J, Chaves C, Appignani B, Breen J, Pao L, Wang A, et al. A reversible posterior leukoencephalopathy syndrome. $\mathrm{N}$ Engl J Med. 1996;334:494-500.

Cite this article as: Singh S, Maji D, Vardhan S. A rare case of early onset severe preeclampsia with PRES. Int J Reprod Contracept Obstet Gynecol 2018;7:1239-42. 